Article

\title{
Effect of the Morphology and Electrical Property of Metal-Deposited ZnO Nanostructures on CO Gas Sensitivity
}

\author{
Sung-Ho Hwang, Young Kwang Kim ${ }^{\circledR}$, Seong Hui Hong and Sang Kyoo Lim * \\ Division of Energy Technology of the Materials Research Institute, DGIST, 333 Techno Jungang-Daero, \\ Hyeonpung-eup, Daegu 42988, Korea; hsungho@dgist.ac.kr (S.-H.H.); kimyk1211@dgist.ac.kr (Y.K.K.); \\ kjyhsh@dgist.ac.kr (S.H.H.) \\ * Correspondence: limsk@dgist.ac.kr; Tel.: +82-053-785-3510
}

Received: 29 September 2020; Accepted: 25 October 2020; Published: 27 October 2020

check for updates

\begin{abstract}
The development of a highly sensitive gas sensor for toxic gases is an important issue in that it can reduce the damage caused by unexpected gas leaks. In this regard, in order to make the sensor accurate and highly responsive, we have investigated which morphology is effective to improve the sensitivity and how the deposited nanoparticle affects the sensitivity by controlling the morphology of semiconductor oxides-either nanorod or nanoplate-and depositing metal nanoparticles on the semiconductor surface. In this study, we compared the CO gas sensitivity for sensors with different morphology (rod and plate) of $\mathrm{ZnO}$ nanostructure with metal nanoparticles (gold and copper) photodeposited and investigated the correlation between the gas sensitivity and some factors such as the morphology of $\mathrm{ZnO}$ and the properties of the deposited metal. Among the samples, $\mathrm{Au} / \mathrm{ZnO}$ nanorod showed the best response ( $86 \%)$ to the exposure of $100 \mathrm{ppm} \mathrm{CO}$ gas at $200{ }^{\circ} \mathrm{C}$. The result showed that the electrical properties due to the deposition of metal species also have a strong influence on the sensor properties such as sensor response, working temperature, the response and recovery time, etc., together with the morphology of $\mathrm{ZnO}$.
\end{abstract}

Keywords: $\mathrm{CO}$ sensor; $\mathrm{ZnO}$; morphology; metal nanoparticle

\section{Introduction}

Carbon monoxide (CO) is a dangerous byproduct derived from the incomplete combustion of petroleum-based fuels. It is very harmful to the human body because it prohibits carrying oxygen to the heart and brain resulting from the rapid formation of carboxyhemoglobin in the lungs [1]. According to the WHO reports, it has been reported that humans die within an hour when exposed to $800 \mathrm{ppm}$ of carbon dioxide, and the recommended safety level is $30 \mathrm{ppm}$ to exposure of $\mathrm{CO}$ for an hour [2]. These standards call for an accurate and rapidly responsive sensor for $\mathrm{CO}$ gas. However, current $\mathrm{CO}$ sensors require a high-temperature condition that reduces the durability to ensure high sensitivity [3]. It is a fascinating issue for scientists to develop a highly sensitive CO gas sensor that not only detects the extremely low concentration of $\mathrm{CO}$ rapidly, but also operates at a low temperature. Therefore, a considerable number of papers have been reported on $\mathrm{CO}$ gas sensors using semiconducting materials such as $\mathrm{ZnO}$ [4], $\mathrm{In}_{2} \mathrm{O}_{3}$ [5,6], $\mathrm{SnO}_{2}$ [3], etc. Among them, $\mathrm{ZnO}$ is one of the best materials for the $\mathrm{CO}$ gas sensor due to its non-toxic nature, and chemical and thermal stability. Therefore, a considerable study has been reported about the synthesis and application of the $\mathrm{CO}$ gas sensor in the form of $\mathrm{ZnO}$ nanostructures (i.e., rod, sphere, and plate), p-type semiconductor/ZnO, metal-deposited $\mathrm{ZnO}$ composites, etc. However, there have been few comparative studies relating to the effect of the morphology of $\mathrm{ZnO}$ on $\mathrm{CO}$ gas sensitivity [7,8]. According to the previous reports, the sensitivity 
toward $\mathrm{CO}$ gas is highly governed by the intrinsic defects of $\mathrm{ZnO}$ such as oxygen vacancies and zinc interstitials. It is well known that these defects act as more favorable active sites to adsorb oxygen species or $\mathrm{CO}$ molecules on the surface [9]. The dopant also affects the response of the gas by variation of the electrical properties of the $\mathrm{ZnO}$. However, it is not fully understood which metal element has a strong influence on $\mathrm{CO}$ gas sensitivity. Although there are several works reported about several synthetic routes to prepare the metal/semiconductor gas sensors via chemical doping [10] or chemical reduction of metal ion [11-13] as listed in Table 1, to our knowledge, there are few studies reporting on metal/semiconductor gas sensors prepared via photodeposition. The photodeposition method has some advantages compared with other methods, in that metal nanoparticles could be not only deposited on the substrate in uniform size and distribution by photodeposition, but also the fabrication process would be easier and more simple than other synthetic routes. The electrical property of the metal nanoparticles might be one of important variables to affect the CO gas response. In order to investigate such effect, generally noble metal would be considered as the best candidates due to their high electrical conductivity and stability. Furthermore, in this work, considering practical application, we wanted to find other metal of high electrical conductivity and stability with the price competitiveness to alternate noble metals. In this aspect, altogether with Au nanoparticle, $\mathrm{Cu}$ one was chosen as one of the candidate materials. Interestingly, it was reported that both $\mathrm{Au}$ and $\mathrm{Cu}$ nanoparticles have important role in CO sensing [14,15]. The presence of Au nanoparticles on the surface of $\operatorname{In}_{2} \mathrm{O}_{3}$ nanowire serves to enhance the $\mathrm{CO}$ oxidation due to a higher oxygen ion chemisorption on the conductive Au nanoparticles surfaces. The coexistence of $\mathrm{ZnO}$ and $\mathrm{Cu}$ metal could enhance the capability of sensor material to adsorb $\mathrm{CO}$ molecules as the copper has active sites to adsorb $\mathrm{CO}$ molecules at both low and high temperature [15]. Therefore, in this study we prepared metal-deposited $\mathrm{ZnO}$ nanorods and nanoplates via photodeposition. Then, we compared the $\mathrm{CO}$ gas sensitivity of each metal-deposited $\mathrm{ZnO}$ nanostructure. The correlation between $\mathrm{CO}$ gas sensitivity and some possible factors, such as morphology of semiconductor, electrical properties, intrinsic properties of metal, and surface characteristics, was discussed.

Table 1. Comparison of the CO sensitivity of metal/semiconductor gas sensors with different synthetic routes.

\begin{tabular}{ccccccc}
\hline $\begin{array}{c}\text { Nano } \\
\text { Particles }\end{array}$ & $\begin{array}{c}\text { Morphology } \\
\mathbf{( Z n O )}\end{array}$ & Synthesis Method & $\begin{array}{c}\text { Operating } \\
\text { Temperature } \\
\left({ }^{\circ} \mathbf{C}\right)\end{array}$ & $\begin{array}{c}\text { Concentration } \\
\text { of CO (ppm) }\end{array}$ & $\begin{array}{c}\text { Sensitivity } \\
\left(\mathbf{R}_{\mathbf{a}} / \mathbf{R}_{\mathbf{g}}\right)\end{array}$ & Ref. \\
\hline $\mathrm{In}$ & Nanoparticle & Sol-gel & 300 & 100 & 5 & {$[10]$} \\
$\mathrm{Au}$ & Nanostar & Hydrothermal & $\mathrm{RT}$ & 100 & 15 & {$[12]$} \\
$\mathrm{Pt}$ & Nanosheet & Hydrothermal/calcination & 180 & 100 & 3.5 & {$[11]$} \\
$\mathrm{Au}$ & Nanorods & Hydrothermal & 150 & 1000 & 12 & {$[13]$} \\
$\mathrm{Pd}$ & Nanowires & VLS growth & RT & 0.1 & 1.02 & {$[13]$} \\
\hline
\end{tabular}

\section{Materials and Methods}

\subsection{Synthesis of ZnO Nanostructures}

$\mathrm{ZnO}$ nanorods were synthesized by the solvothermal method [16]. First, a zinc acetate dihydrate solution of $0.5 \mathrm{M}\left(\mathrm{Zn}\left(\mathrm{CH}_{3} \mathrm{COOH}\right)_{2} \bullet 2 \mathrm{H}_{2} \mathrm{O}, 99 \%\right.$, Daejung, Korea) was prepared by stirring in ethanol for $10 \mathrm{~min}$. Then, sodium hydroxide (NaOH, 99\%, Daejung, Korea) was added to the solution so that the concentration of $\mathrm{NaOH}$ was $5 \mathrm{M}$, followed by stirring for $30 \mathrm{~min}$. After transferring the mixed solution to an autoclave, the solution was stirred at $150{ }^{\circ} \mathrm{C}$ for $2 \mathrm{~h}$ and cooled down to room temperature. The precipitates were then washed with distilled water until the $\mathrm{pH}$ of precipitates became neutral and dried in a vacuum oven at $70{ }^{\circ} \mathrm{C}$ for $12 \mathrm{~h}$. ZnO nanoplates were synthesized by the same method of the $\mathrm{ZnO}$ nanorods except for changing the zinc precursor from $\mathrm{Zn}\left(\mathrm{CH}_{3} \mathrm{COOH}\right)_{2} \bullet 2 \mathrm{H}_{2} \mathrm{O}$ to zinc chloride $\left(\mathrm{ZnCl}_{2}, 99 \%\right.$, Daejung, Korea). Then, uniform $\mathrm{ZnO}$ nanorods and nanoplates were obtained (Figure S1). 


\subsection{Photodeposition of Metals on ZnO Nanostructures}

The metal-deposited $\mathrm{ZnO}$ nanostructures were prepared by the photodeposition method [17,18]. Briefly, $\mathrm{ZnO}$ nanorods or $\mathrm{ZnO}$ nanoplates $\left(0.5 \mathrm{~g} \mathrm{~L}^{-1}\right)$ were dispersed in $20 \mathrm{wt} \%$ methanol solution Then, the metal precursor was added into the mixture solution so that the concentration of metal was 0.1 $\mathrm{mM}$. The metal precursor for gold and copper was selected as gold chloride $\left(\mathrm{AuCl}_{3}\right.$, Sigma-Aldrich, St. Louis, MO, USA) and copper acetate monohydrate $\left(\mathrm{Cu}\left(\mathrm{CH}_{3} \mathrm{COOH}\right)_{2} \bullet \mathrm{H}_{2} \mathrm{O}\right.$, Sigma-Aldrich, St. Louis, MO, USA), respectively. It was found that the crystal phase of $\mathrm{ZnO}$ nanostructure was not affected by UV irradiation to the suspension as shown in XRD patterns of Figure S2. However, the amount of metals deposited on the $\mathrm{ZnO}$ nanostructures would be increased with increasing the UV intensity and deposition time, and then saturated. As the gas sensing response of metal/semiconductor sensor would be closely related to the amount of deposited metal, the effect of UV intensity and deposition time (irradiation time) upon the amount of metal deposited on $\mathrm{ZnO}$ nanostructures was checked using $0.1 \mathrm{mM}$ of metal precursors to optimize the deposition amount of each metal. The deposition amount of metals increased with increasing the UV intensity up to $450 \mathrm{~W}$ for $30 \mathrm{~min}$ in deposition process. The content of deposited metal was observed to be saturated at condition over $30 \mathrm{~min}$. On the basis of this result, we set the experimental condition for the deposition of metal as UV intensity of $450 \mathrm{~W}$ for $30 \mathrm{~min}$ in order to obtain the best gas response throughout the optimal loading content of metal nanoparticles deposited on $\mathrm{ZnO}$ nanostructures. Therefore, after transferring the mixed solution into a cylindrical quartz reactor, a UV light $(\lambda=254 \mathrm{~nm}, 450 \mathrm{~W})$ was irradiated to a mixed solution for $30 \mathrm{~min}$. The resultant precipitates were washed with distilled water and dried at room temperature for $24 \mathrm{~h}$. Then, metal deposited $\mathrm{ZnO}$ nanostructures were obtained and characterized.

\subsection{Surface Characterization}

High-resolution morphological images of the $\mathrm{ZnO}$ nanostructures and metal deposited $\mathrm{ZnO}$ nanostructures were obtained using a scanning electron microscope (SEM, SU8020, Hitachi, Tokyo, Japan) and transmission electron microscope (TEM, HF-3300, Hitachi, Tokyo, Japan). The crystal structures of the samples were analyzed using an X-ray diffractometer (Empyrean Alpha-1, Malvern Panalytical Ltd., Malvern, UK) with $\mathrm{Cu} \mathrm{K} \alpha$ radiation $(\lambda=1.54178 \AA$ A ) and operating at $40 \mathrm{kV}, 30 \mathrm{~mA}$, and a scan rate of $0.03 \mathrm{~s}^{-1}$. The chemical states of the samples were analyzed by an $X$-ray photoelectron spectrometer (Escalab 250 Xi, Thermo Fisher Scientific, Waltham, MA, USA). The deposition amount of inorganic elements in the samples was analyzed by inductively coupled plasma mass spectrometer (iCAP7400DUO, Thermo Fisher Scientific, Waltham, MA, USA). A photoluminescence experiment was performed with a $325 \mathrm{~nm}$ He-Cd laser $(1 \mathrm{~K}, 50 \mathrm{~mW}$, Kimmon Koha Co. Ltd., Tokyo, Japan). The Brunauer-Emmett-Teller (BET) surface area of ZnO nanostructures was calculated from nitrogen adsorption-desorption isotherm at $77 \mathrm{~K}$ (ASAP2020, Micrometrics, Norcross, GA, USA). The effective surface areas were estimated at a relative pressure $\left(\mathrm{P} / \mathrm{P}_{0}\right)$ ranging from 0.06 to 1 . The electrical conductivity of the samples was measured using a 4-point probe system (CMT-SR200N, AIT, Suwon, Korea).

\subsection{Measurement of CO Gas Sensitivity}

The sensor was fabricated by dropping $\mathrm{ZnO}$ nanostructures or metal deposited $\mathrm{ZnO}$ nanostructures gels on a sapphire substrate with pre-patterned Pt electrodes (Figure 1). The gels were made by grinding $10 \mathrm{mg}$ of $\mathrm{ZnO}$ nanostructures or metal-deposited $\mathrm{ZnO}$ nanostructures with $0.25 \mathrm{~mL}$ of distilled water in an agate mortar. A precise micropipette (Eppendorf Reference ${ }^{\circledR}$ 2, Eppendorf, Germany) was then used to deposit the solution. After dropping $10 \mu \mathrm{L}$ of $\mathrm{ZnO}$ nanostructures or metal-deposited $\mathrm{ZnO}$ nanostructures, the substrate was dried in the air [19]. The CO gas sensitivity of the as-prepared sensors was measured by a computer-based sensing system consisting of three parts: (i) a controlling device of gas (PXI-DAQ system, National Instrument, Austin, TX, USA) equipped with a mass flow controller (Brooks 5850E, Brooks instrument, Hatfield, PA, USA), (ii) a semiconductor characterization 
system (4200SCS, Keithley, Cleveland, OH, USA), and (iii) a chamber (size: $20 \mathrm{~cm} \times 20 \mathrm{~cm} \times 10 \mathrm{~cm}$ ) equipped with a heater for sensors (E3631A, Agilent Technologies, Inc., Wood dale, IL, USA). The gas response was defined as the percentage change in resistance of the sensor upon exposure of $\mathrm{CO}$ gas $\left(\left(R_{a}-R_{g}\right) / R_{a}\right) \times 100(\%)$, where $R_{a}$ and $R_{g}$ are the resistance in air and $C O$, respectively.

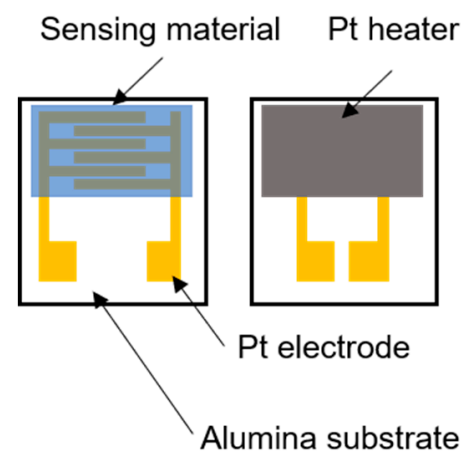

Figure 1. The schematic illustration of the sensor device.

\section{Results and Discussion}

\subsection{Surface Characterization of ZnO Nanostructures and Metal-Deposited ZnO Nanostructures}

The local microstructure of all the samples were showed in Figure 2, in which nanorods were much smaller than nanoplates and very small metal nanoparticles such as copper and gold nanoparticles were observed to be deposited on $\mathrm{ZnO}$ nanorods and nanoplates. In the case of the overall morphology, both $\mathrm{ZnO}$ nanorods and nanoplates were observed to exhibit uniform overall morphology and distribution (SEM images of Figure S1). On the other hand, to investigate the phase of metal-deposited $\mathrm{ZnO}$ nanostructures, we carried out XRD and SAED patterns analysis. While the XRD in Figure S2 showed that only the crystal phase of $\mathrm{ZnO}$ alone was observed in all the samples due to the low crystallinity of small metal nanoparticles $(\sim 10 \mathrm{~nm})$ and smaller content of deposited metal for that of $\mathrm{ZnO}$, it could be confirmed that, from the TEM images and onset SAED patterns of Figure 2, the deposited metal species were stabilized on $\mathrm{ZnO}$ nanostructures as metal phase. On the other hand, it seemed in Figure 2 that a larger amount of nanoparticles was deposited on the $\mathrm{ZnO}$ nanoplate than on the $\mathrm{ZnO}$ nanorod. It was also shown that the amount of metal deposited on $\mathrm{ZnO}$ nanostructures were varied according to metal species. The exact amount of deposited metal on $\mathrm{ZnO}$ nanostructures was confirmed by ICP-MS measurement (Table 2). The molar ratios of $\mathrm{Au} / \mathrm{Zn}$ in $\mathrm{Au} / \mathrm{ZnO}$ nanostructures were calculated to be 0.327 and 0.497 for nanorods and nanoplates, respectively, while those of $\mathrm{Cu} / \mathrm{Zn}$ in $\mathrm{Cu} / \mathrm{ZnO}$ nanostructures were 0.061 and 0.084 for nanorods and nanoplates, respectively. This showed that all the metals were more largely deposited on the $\mathrm{ZnO}$ nanoplates than nanorods as well as $\mathrm{Au}$ nanoparticles were much more largely deposited than $\mathrm{Cu}$ nanoparticles in both $\mathrm{ZnO}$ nanorod and nanoplate. These results could be understood due to different electrostatic interactions or weak van der Waals forces at the surface of the samples induced by the morphology of $\mathrm{ZnO}$ and the electrical property of metal species [20]. In other words, the amount of deposited-metal was closely related to the $\mathrm{pH}$ of the metal precursor suspension and the surface charge of the $\mathrm{ZnO}$ nanostructure at that $\mathrm{pH}[21,22]$. In Figure 3a, we present the Zeta potential of $\mathrm{ZnO}$ nanostructures in metal precursor solution (black) and $\mathrm{pH}$ of metal precursor solution (gray). The $\mathrm{ZnO}$ suspensions with Au precursor were the most basic, and the surface charge of $\mathrm{ZnO}$ has the greatest negative charge among the $\mathrm{ZnO}$ suspensions with metal precursors, which enabled strong interaction with metal cations. Therefore, it could be expected that the gold nanoparticles would be more largely deposited than Cu nanoparticles. It was also notable in Table 1 that the electrical conductivity was higher in metal-deposited $\mathrm{ZnO}$ nanorods than in metal-deposited $\mathrm{ZnO}$ nanoplates due to the combined effect of the metal deposited amount and morphology of $\mathrm{ZnO}$. The XPS Au $4 \mathrm{f}$ spectra of $\mathrm{Au} / \mathrm{ZnO}$ nanostructures and the XPS Cu 2p spectra of $\mathrm{Cu} / \mathrm{ZnO}$ nanostructures are shown in Figure 3b,c. Two metallic Au $4 \mathrm{f}$ peaks with the binding 
energies at 84.0 and $87.7 \mathrm{eV}$ corresponding to $\mathrm{Au} 4 \mathrm{f}_{7 / 2}$ and $\mathrm{Au} 4 \mathrm{f}_{5 / 2}$, respectively, were observed in the XPS spectra of metal-deposited samples with gold chloride [23]. In the case of copper acetate monohydrate, two metallic $\mathrm{Cu} 2 \mathrm{p}$ peaks were observed in the samples with binding energies at 932.55 and $952.55 \mathrm{eV}$ corresponding to $\mathrm{Cu} 2 \mathrm{p}_{3 / 2}$ and $\mathrm{Cu} 2 \mathrm{p}_{1 / 2}$, respectively $[18,24]$. Therefore, from the ICP and XPS results, it was confirmed that the metallic nanoparticles $\left(\mathrm{Cu}^{0}\right.$ or $\left.\mathrm{Au}^{0}\right)$ were well deposited on each $\mathrm{ZnO}$ nanostructure via the photodeposition method.

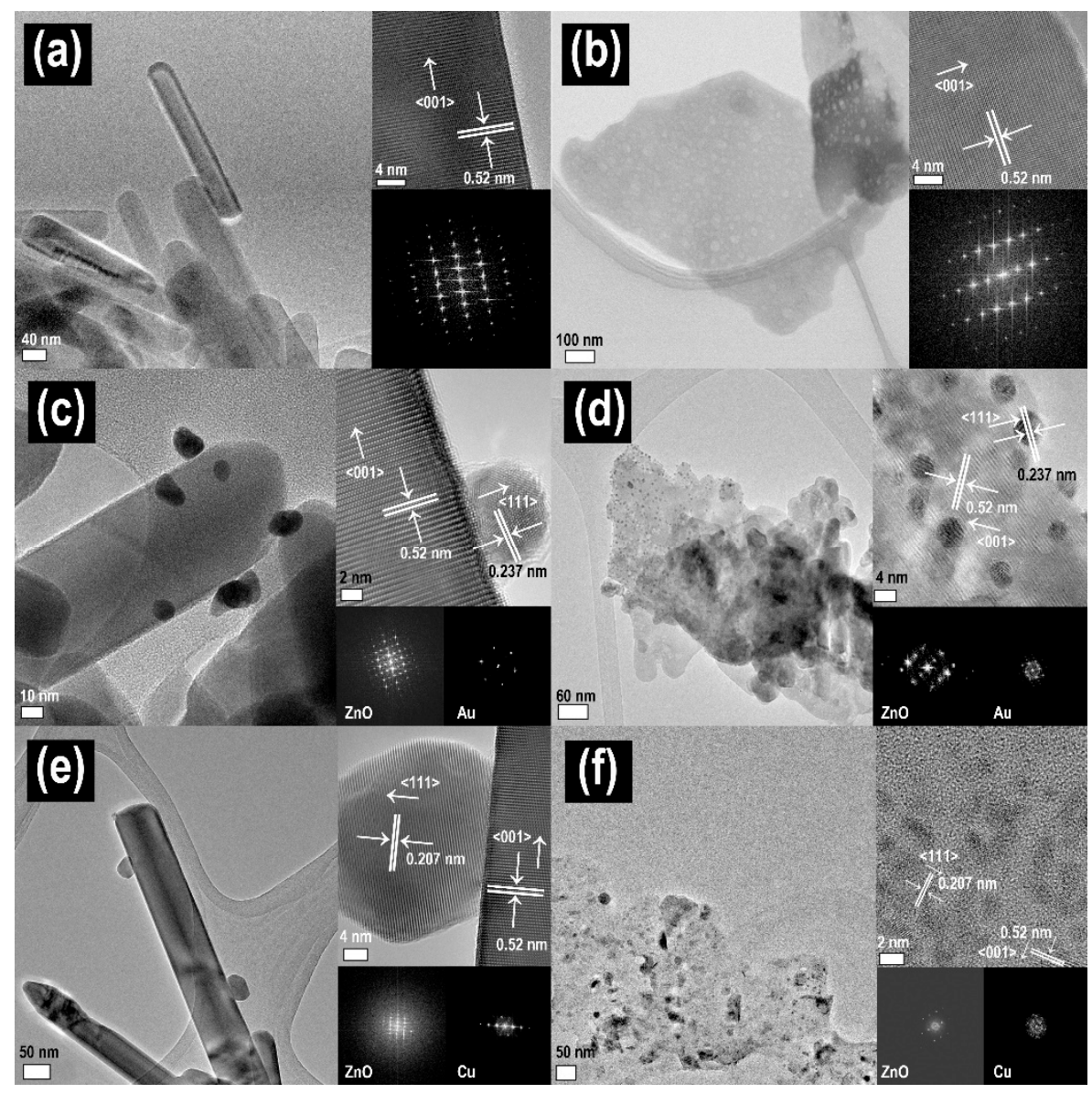

Figure 2. TEM images and selected area electron diffraction patterns of metal-deposited $\mathrm{ZnO}$ nanostructures: (a) $\mathrm{ZnO}$ nanorod, (b) $\mathrm{ZnO}$ nanoplate, (c) $\mathrm{Au} / \mathrm{ZnO}$ nanorod (d) $\mathrm{Au} / \mathrm{ZnO}$ nanoplate, (e) $\mathrm{Cu} / \mathrm{ZnO}$ nanorod, and (f) $\mathrm{Cu} / \mathrm{ZnO}$ nanoplate.

Table 2. The elemental ratio in different metal-deposited $\mathrm{ZnO}$ nanostructures and the electrical conductivity of the metal-deposited $\mathrm{ZnO}$ nanostructures.

\begin{tabular}{ccccc}
\hline Sample & Metal (mM) & Zn $(\mathbf{m M})$ & Metal/Zn $\mathbf{~}^{\mathbf{2}}$ & $\begin{array}{c}\text { Electrical } \\
\text { Conductivity } \\
\mathbf{( S / m )}\end{array}$ \\
\hline ZnO nanorod & - & 3.313 & - & $7.345 \times 10^{-7}$ \\
$\mathrm{Au} / \mathrm{ZnO}$ nanorod & 1.040 & 3.186 & 0.327 & $6.327 \times 10^{-6}$ \\
$\mathrm{Cu} / \mathrm{ZnO}$ nanorod & 0.185 & 3.048 & 0.061 & $1.057 \times 10^{-6}$ \\
ZnO nanoplate & - & 3.061 & - & $6.148 \times 10^{-7}$ \\
$\mathrm{Au} / \mathrm{ZnO}$ nanoplate & 1.501 & 3.019 & 0.497 & $5.113 \times 10^{-6}$ \\
$\mathrm{Cu} / \mathrm{ZnO}$ nanoplate & 0.254 & 3.030 & 0.084 & $1.044 \times 10^{-6}$ \\
\hline
\end{tabular}

${ }^{1}$ The molar ratio of the photodeposited metal ( $\mathrm{Au}$ or $\mathrm{Cu}$ ) vs. zinc. 

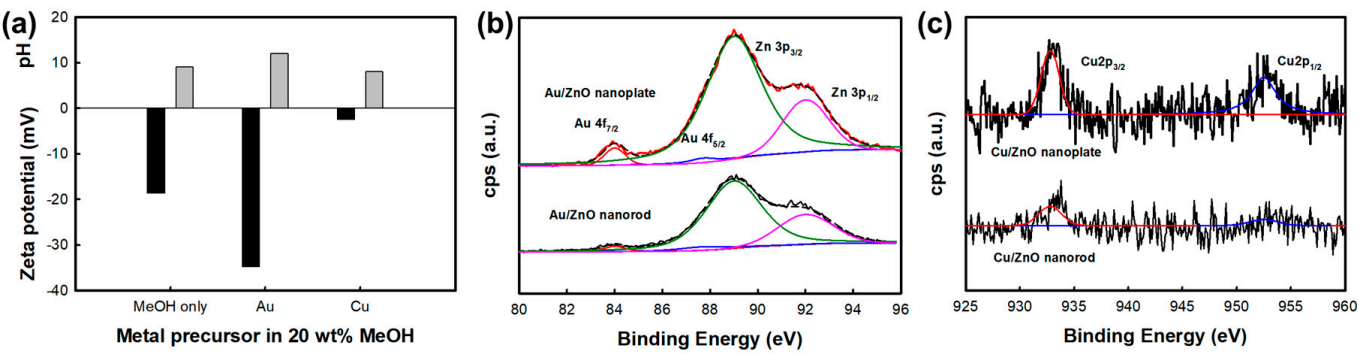

Figure 3. (a) Zeta potential of $\mathrm{ZnO}$ nanostructures in metal precursor solution (black bar) and $\mathrm{pH}$ of metal precursor solution (gray bar). The concentration of the metal precursor is $0.1 \mathrm{mM}$, (b) XPS Au $4 \mathrm{f}$ spectra of $\mathrm{Au} / \mathrm{ZnO}$ nanostructures, and (c) XPS Cu 2p spectra of $\mathrm{Cu} / \mathrm{ZnO}$ nanostructures.

\subsection{CO Gas Sensitivity of $\mathrm{ZnO}$ Nanostructures and Metal-Deposited $\mathrm{ZnO}$ Nanostructures}

Figure 3 shows the gas responses of the pristine $\mathrm{ZnO}$ nanostructures and metal-deposited $\mathrm{ZnO}$ nanostructures to a $100 \mathrm{ppm}$ of carbon monoxide as a function of working temperature. It is observed that the responses of the pristine $\mathrm{ZnO}$ nanorod and nanoplate increase with an increase of the working temperature up to $300{ }^{\circ} \mathrm{C}$, then decrease with a further increase in working temperature. The primary oxygen species on the surface of pristine $\mathrm{ZnO}$ nanostructure can be known to be changed by temperature. Monovalent oxygen anions $\left(\mathrm{O}_{2}{ }^{-}\right.$and $\left.\mathrm{O}^{-}\right)$can exist at below $300{ }^{\circ} \mathrm{C}$. However, divalent oxygen anion $\left(\mathrm{O}^{2-}\right)$, which induces larger resistance changes via a two-electron reaction, can exist at over $300{ }^{\circ} \mathrm{C}$ [25]. Simultaneously, the desorption of oxygen species increases with a further rise in temperature. Therefore, the optimal working temperature of the pristine $\mathrm{ZnO}$ nanostructures can be decided by the combined effect of two factors, the formation of divalent oxygen anion and the rate of adsorptive reaction, at a certain temperature. However, the optimal working temperature becomes lower to $200{ }^{\circ} \mathrm{C}$ in all the metal-deposited $\mathrm{ZnO}$ nanostructures. It is attributed to the lowering of the activation energy for chemisorption of $\mathrm{CO}$ gas by metals [11].

On the other hand, in Figure 4, Figure 5 and Table 3, the $\mathrm{Au} / \mathrm{ZnO}$ nanorods exhibit the best response among all the samples. $\mathrm{The} \mathrm{Cu} / \mathrm{ZnO}$ nanorods show an intermediate response. The lowest response is observed in the pristine $\mathrm{ZnO}$ nanoplates. Compared with the response of the $\mathrm{ZnO}$ nanorods, the responses of the $\mathrm{ZnO}$ nanoplates are observed to be slightly decreased, and the response is increased in the following order; $\mathrm{Au} / \mathrm{ZnO}$ nanoplate, $\mathrm{Cu} / \mathrm{ZnO}$ nanoplate, and $\mathrm{ZnO}$ nanoplate, which is the same increasing order of responses in $\mathrm{ZnO}$ nanorods. That is, it has been observed that the $\mathrm{CO}$ gas response is higher in $\mathrm{ZnO}$ nanorods than in $\mathrm{ZnO}$ nanoplates due to the difference in morphology. As shown in Figure 2, $\mathrm{ZnO}$ nanorods would be expected to have a higher surface area than nanoplates with a much larger particular size. In Figure 6 and Table 4, it could be confirmed that nanorod morphology showed a higher relative surface area and larger pore volume due to their mesoporosity than nanoplate one. In addition, it could become a good reason for a higher response of nanorod morphology that the high aspect ratio and interconnectivity of the nanorods would result in better electron transport along the axial direction and the creation of more electron paths [26]. Actually, it was found that the electrical conductivity of nanorods was higher than that of corresponding nanoplates in Table 1. 

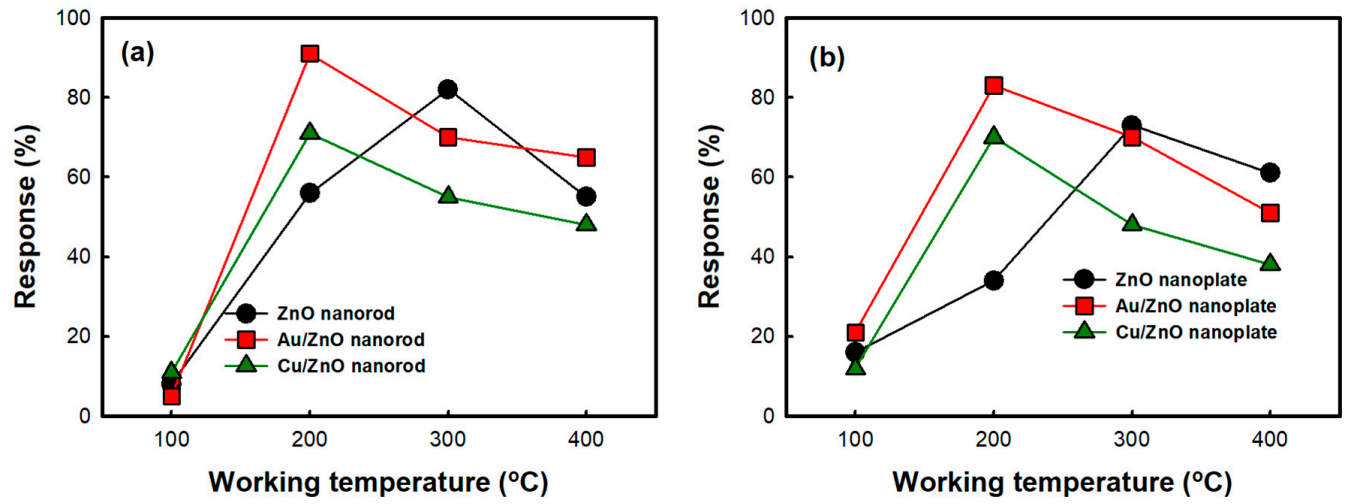

Figure 4. The gas response of the samples up to $100 \mathrm{ppm} \mathrm{CO}$ as a function of working temperature (a) $\mathrm{ZnO}$ nanorod and metal-deposited $\mathrm{ZnO}$ nanorods (b) $\mathrm{ZnO}$ nanoplate and metal-deposited $\mathrm{ZnO}$ nanoplates.
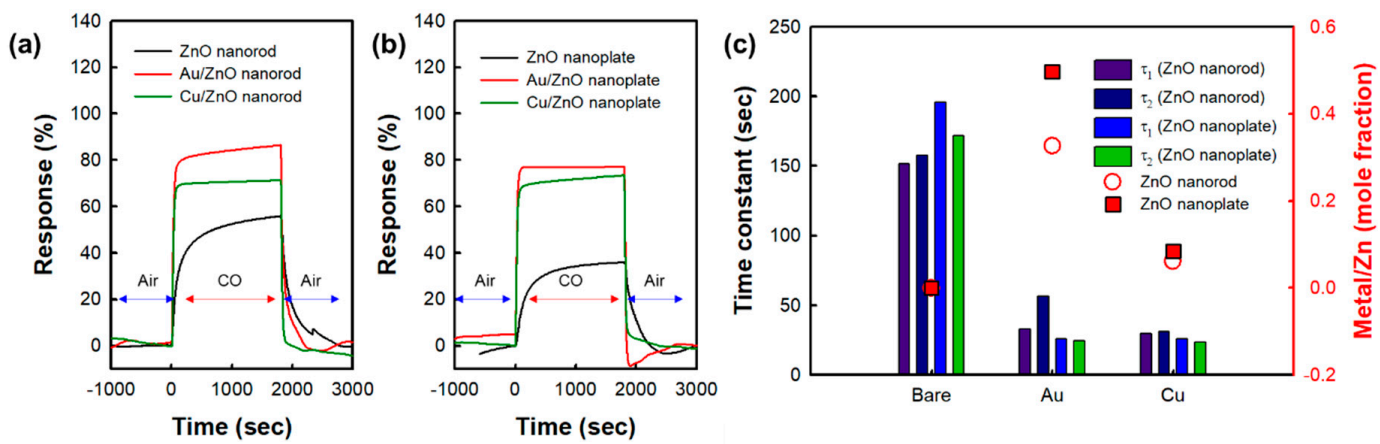

Figure 5. The actual response transient of pristine $\mathrm{ZnO}$ nanostructures and metal-deposited $\mathrm{ZnO}$ nanostructures to $100 \mathrm{ppm} \mathrm{CO}$ gas at $200{ }^{\circ} \mathrm{C}$. (a) $\mathrm{ZnO}$ nanorod and metal-deposited $\mathrm{ZnO}$ nanorods. (b) $\mathrm{ZnO}$ nanoplate and metal-deposited $\mathrm{ZnO}$ nanoplates. (c) Response and recovery time of pristine $\mathrm{ZnO}$ nanostructures and metal-deposited $\mathrm{ZnO}$ nanostructures.

Table 3. The gas response, response time, and recovery time of the samples.

\begin{tabular}{cccc}
\hline Sample & ${ }^{\mathbf{1}}$ Gas Response (\%) & ${ }^{\mathbf{2}}$ Response Time $\boldsymbol{\tau}_{\mathbf{1}} \mathbf{( s e c )}$ & ${ }^{\mathbf{3}}$ Recovery Time $\boldsymbol{\tau}_{\mathbf{2}}$ (sec) \\
\hline ZnO nanorod & 55.96 & 151.519 & 157.970 \\
$\mathrm{Au} / \mathrm{ZnO}$ nanorod & 86.45 & 32.864 & 56.599 \\
$\mathrm{Cu} / \mathrm{ZnO}$ nanorod & 71.39 & 29.851 & 31.108 \\
$\mathrm{ZnO}$ nanoplate & 36.06 & 195.691 & 172.005 \\
$\mathrm{Au} / \mathrm{ZnO}$ nanoplate & 77.34 & 26.053 & 24.749 \\
$\mathrm{Cu} / \mathrm{ZnO}$ nanoplate & 70.51 & 26.172 & 23.743 \\
\hline
\end{tabular}

${ }^{1}$ Gas response of the sample at the working temperature of $200{ }^{\circ} \mathrm{C},{ }^{2} \Delta \mathrm{R}=\Delta \mathrm{R}_{\max }\left(1-e^{-\frac{t}{\tau_{1}}}\right),{ }^{3} \Delta \mathrm{R}=\Delta \mathrm{R}_{\max } e^{-\frac{t}{\tau_{2}}}$. 


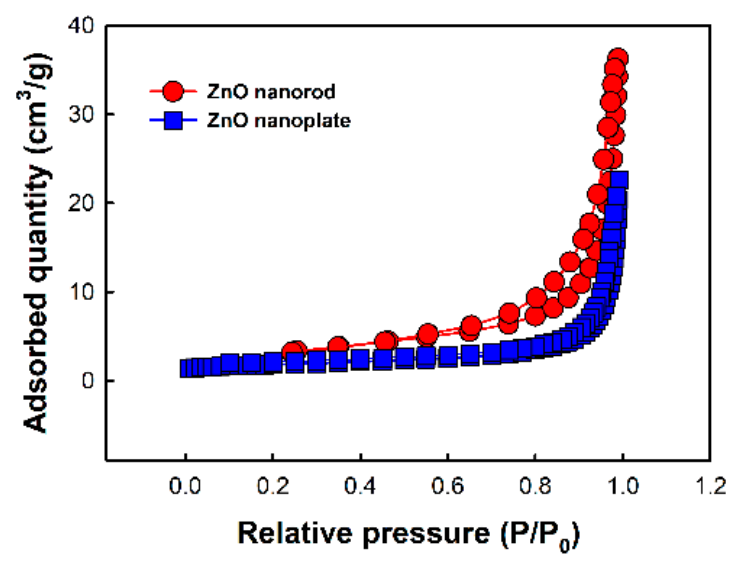

Figure 6. The Brunauer-Emmett-Teller (BET) surface area measured from $\mathrm{N}_{2}$ adsorption and desorption isotherms at $77 \mathrm{~K}$.

Table 4. BET surface area and pore characteristics.

\begin{tabular}{cccc}
\hline Sample & BET Surface Area $\left(\mathbf{m}^{\mathbf{2}} / \mathbf{g}\right)$ & Pore Volume $\mathbf{( \mathbf { c m } ^ { 3 } / \mathbf { g } )}$ & Pore Size $(\mathbf{n m})$ \\
\hline ZnO nanorod & 11.3021 & 0.040563 & 12.945 \\
ZnO nanoplate & 5.9611 & 0.034951 & 23.453 \\
\hline
\end{tabular}

On the other hand, some factors were also selected to identify the reasons for the improvement of gas sensitivity in metal-deposited $\mathrm{ZnO}$ nanostructures relative to the pristine $\mathrm{ZnO}$ nanostructures. The loading amount of metal, a metallic component, and the work function of metal might influence the sensitivity of the sensors. Therefore, we investigated the correlation between those factors and sensitivity. The electrical properties of the sample can affect the adsorption of the target gas ions on the surface of the sample, resulting in the change of the resistance related to the gas sensitivity of the sample. Therefore, in this work, we will discuss the relationship between the electrical conductivity, the work function of the samples, and their gas sensitivity [27]. $\mathrm{ZnO}$ is an n-type semiconductor that contains free electrons, and, after photodeposition of metal on the $\mathrm{ZnO}$ nanostructures, free electrons from the metal are released into the $\mathrm{ZnO}$ structure and the number of free electrons will be greater [28]. According to the principle of $\mathrm{CO}$ gas sensing, the oxygen species are adsorbed on the surface of the n-type semiconductor gas sensor, which results in a high resistance in the atmosphere due to the formation of a depletion layer. After exposure to $\mathrm{CO}$ gas, the adsorbed oxygen species reacted with $\mathrm{CO}$ molecules, which releases the free electrons back to the $\mathrm{ZnO}$ structure, and brings about a resistance change of the sample, and then the level of resistance change determines the response of the sensor. It is reported that the high electrical conductivity and work function of metal can promote the adsorption rate of the exposed gas molecules and the level of resistance changes. The response of the sensor is related to the creation of the Schottky barrier between the metal clusters and $\mathrm{ZnO}$ grains. In the ambient air, oxygen molecules are adsorbed on the metal clusters, increasing their work function and decreasing their electrical conductivity. On the contrary, in the presence of $\mathrm{CO}$ gas, desorption of oxygen molecules from the deposited metal surface leads to a decrease in the work function and an increase in electrical conductivity. According to the gas-sensing principle, we can predict that a better response can be achieved by inducing a larger change in the work function or electrical conductivity of the sensor under the exposure of air and CO. From this point of view, the metal-deposited $\mathrm{ZnO}$ nanostructures, due to the larger electrical conductivity and higher work function of deposited-metal relative to $\mathrm{ZnO}$, could bring about a larger difference in the height of the Schottky barrier, leading to an improved gas response $[29,30]$. It was found in Table 1 that the electrical conductivity of the samples became higher in the order of $\mathrm{Au}$-deposited $\mathrm{ZnO}$ nanostructures, $\mathrm{Cu}$-deposited ones, and pristine ones due to the actual fraction of metal-deposited on $\mathrm{ZnO}$ nanostructures. The work function of the deposited metal also increased in the order of $\mathrm{Au}(5.10-5.47 \mathrm{eV})$ and $\mathrm{Cu}(4.53-5.10 \mathrm{eV})$, which was 
reported elsewhere. As shown in Figure 7, due to the higher work function of Au relative to $\mathrm{ZnO}$, electrons migrate from the conduction band of $\mathrm{ZnO}$ to $\mathrm{Au}$ in order to equalize the Fermi levels and form Schottky heterojunctions at the interface of $\mathrm{Au}$ and $\mathrm{ZnO}$ nanostructures, which led to the reduction of conduction volume. Such reduction of conduction volume will contribute to the enhanced sensor response in $\mathrm{Au} / \mathrm{ZnO}$ [29]. Analogous to the case of $\mathrm{Au} / \mathrm{ZnO}$, such reduction in $\mathrm{Cu} / \mathrm{ZnO}$ will also occur but be smaller than that in $\mathrm{Au} / \mathrm{ZnO}$ due to the lower work function of $\mathrm{Cu}$ relative to Au. Therefore, we can expect that the Au-deposited $\mathrm{ZnO}$ nanorods, which have the highest electrical conductivity and work function of deposited-metal, would elicit the best response to the exposure of CO gas.

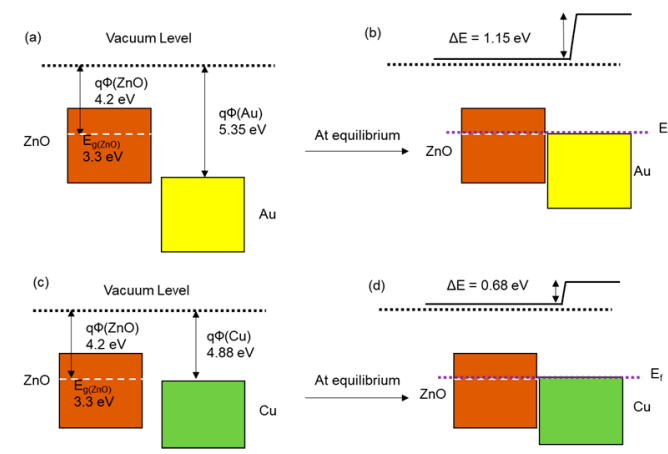

Figure 7. (a) Energy levels of $\mathrm{ZnO}$ and $\mathrm{Au}$; (b) formation of heterojunction barrier. (c) Energy levels of $\mathrm{ZnO}$ and $\mathrm{Cu} ;(\mathrm{d})$ formation of heterojunction barrier.

In general, it is well known that the surface oxygen of the sample also influences the gas response. Therefore, we analyzed the amount of surface oxygen of the sample by XPS analysis. To estimate the fraction of each component of surface oxygen, the XPS O1s spectra were deconvoluted using the Shirley method. Figure 8 shows the XPS O1s spectra of the ZnO nanostructures and metal-deposited $\mathrm{ZnO}$ structures. It was found that the samples were composed of three kinds of surface oxygen with different fractions. The peaks in XPS O1s spectra assigned at 530.3, 531.2, and $532.6 \mathrm{eV}$ were lattice oxygen, oxygen ions in the oxygen-deficient regions caused by oxygen vacancy, and chemisorbed oxygen, respectively [31,32]. As shown in Table 5, it was found that the peak at $\sim 531.2 \mathrm{eV}$ attributed to oxygens in oxygen-deficient regions oxygen vacancies was larger in the $\mathrm{ZnO}$ nanorods than in the $\mathrm{ZnO}$ nanoplates, reflecting more oxygen vacancies in $\mathrm{ZnO}$ nanorod than in $\mathrm{ZnO}$ nanoplate. In addition, because of the larger peak area in metal-deposited $\mathrm{ZnO}$ nanostructures than pure ones, it was considered that the deposition of metal nanoparticles also increases the creation of the oxygen vacancies in the samples. Therefore, it was confirmed that the morphology of $\mathrm{ZnO}$ nanostructures and the deposition of metal on the $\mathrm{ZnO}$ nanostructures affect the amount of surface oxygen of the samples. Among the samples, $\mathrm{Au} / \mathrm{ZnO}$ nanorod exhibited the largest portion of oxygen vacancies, which was also believed to have contributed to the response to the $\mathrm{CO}$ gas. 

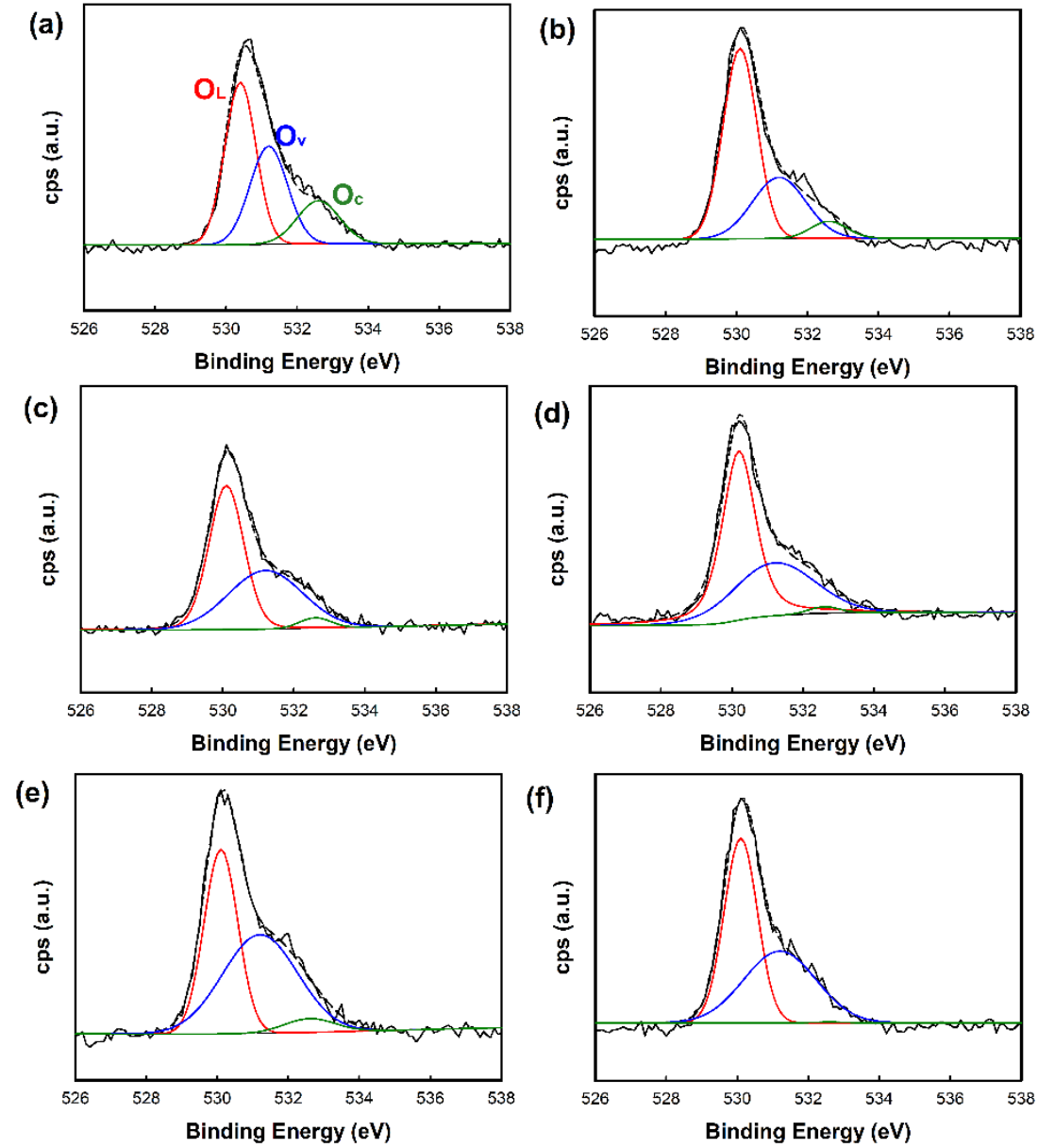

Figure 8. XPS O1s spectra of the $\mathrm{ZnO}$ nanostructures and metal-deposited $\mathrm{ZnO}$ nanostructures: (a) $\mathrm{ZnO}$ nanorod, (b) $\mathrm{ZnO}$ nanoplate, (c) $\mathrm{Au} / \mathrm{ZnO}$ nanorod, (d) $\mathrm{Au} / \mathrm{ZnO}$ nanoplate, (e) $\mathrm{Cu} / \mathrm{ZnO}$ nanorod, and (f) $\mathrm{Cu} / \mathrm{ZnO}$ nanoplate.

Table 5. Surface oxygen components in $\mathrm{ZnO}$ nanostructures and metal-deposited $\mathrm{ZnO}$ nanostructures.

\begin{tabular}{cccc}
\hline Sample & $\mathbf{O}_{\mathbf{L}}{ }^{\mathbf{1}} \mathbf{( \% )}$ & $\mathbf{O}_{\mathbf{v}}{ }^{\mathbf{2}} \mathbf{( \% )}$ & $\left.\mathbf{O}_{\mathbf{c}}{ }^{\mathbf{3}} \mathbf{\%}\right)$ \\
\hline ZnO nanorod & 39.63 & 46.39 & 13.98 \\
$\mathrm{Au} / \mathrm{ZnO}$ nanorod & 43.49 & 51.66 & 4.85 \\
$\mathrm{Cu} / \mathrm{ZnO}$ nanorod & 52.78 & 43.91 & 3.31 \\
ZnO nanoplate & 62.59 & 31.47 & 5.94 \\
$\mathrm{Au} / \mathrm{ZnO}$ nanoplate & 50.00 & 48.31 & 1.69 \\
$\mathrm{Cu} / \mathrm{ZnO}$ nanoplate & 54.20 & 45.60 & 0.20 \\
\hline
\end{tabular}

${ }^{1}$ lattice oxygen; ${ }^{2}$ oxygen around vacancy; ${ }^{3}$ chemisorbed oxygen.

The response time and stability of the sensor are also important factors to the practical application of the sensor $[33,34]$. Therefore, we measured the response time of the sensors by repeating exposure to $\mathrm{CO}$ and air in one cycle. Figure 9 shows the representative actual response transient, response time, and recovery time of the as-prepared sensors. The response time and recovery time are listed in Table 3. In pristine $\mathrm{ZnO}$ nanostructures, the response time is up to $200 \mathrm{~s}$. However, that of metal-deposited $\mathrm{ZnO}$ nanostructures is below $35 \mathrm{~s}$. This result was also observed similarly in recovery time and it was found that the response and recovery times were observed to be much shorter in the metal-deposited $\mathrm{ZnO}$ nanostructures than in pristine ones. Therefore, the deposition of metals such as $\mathrm{Au}$ and $\mathrm{Cu}$ might have an influence on the significant reduction of both the response and recovery time. 

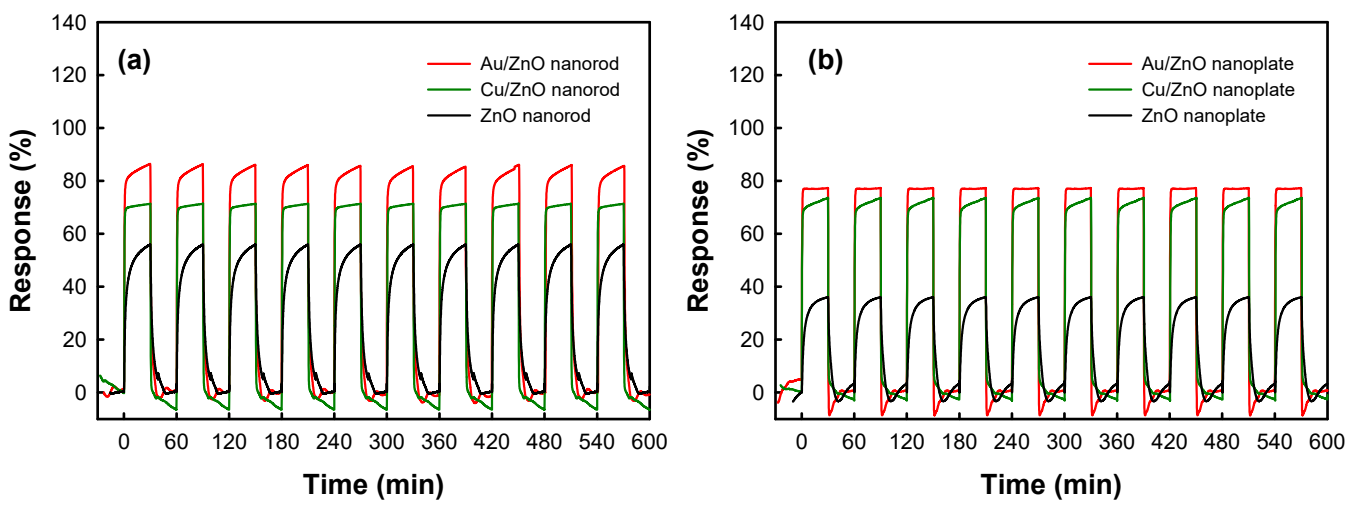

Figure 9. Gas response of the $\mathrm{ZnO}$ nanostructure and metal deposited $\mathrm{ZnO}$ nanostructures during 10 successive cycles of exposure to $100 \mathrm{ppm} \mathrm{CO}$ and air alternately at $200{ }^{\circ} \mathrm{C}$. (a) $\mathrm{ZnO}$ nanorod and metal-deposited $\mathrm{ZnO}$ nanorods (b) $\mathrm{ZnO}$ nanoplate and metal-deposited $\mathrm{ZnO}$ nanoplates.

The reproducibility test was also carried out using metal-deposited $\mathrm{ZnO}$ nanostructures and pristine $\mathrm{ZnO}$ nanostructures under the reversible exposure to $100 \mathrm{ppm} \mathrm{CO}$ gas at $200{ }^{\circ} \mathrm{C}$ as shown in Figure 9. It was found that the response, response time, and recovery time of the metal-deposited $\mathrm{ZnO}$ nanostructures were almost identical during 10 reversible cycles. As shown in Figure 10, we also investigated the change of chemical state of metal in the metal-deposited $\mathrm{ZnO}$ nanostructures after 10 successive cycles of exposure to $100 \mathrm{ppm} \mathrm{CO}$ gas. $\mathrm{Au} 4 \mathrm{f}$ and $\mathrm{Cu} 2 \mathrm{p}$ spectra of samples before and after gas-sensing test did not show any prominent difference, reflecting that there was no change in the chemical state of $\mathrm{Au}$ and $\mathrm{Cu}$ nanoparticles after gas-sensing test. Those results would also indicate that the metal-deposited $\mathrm{ZnO}$ nanostructures have good stability.
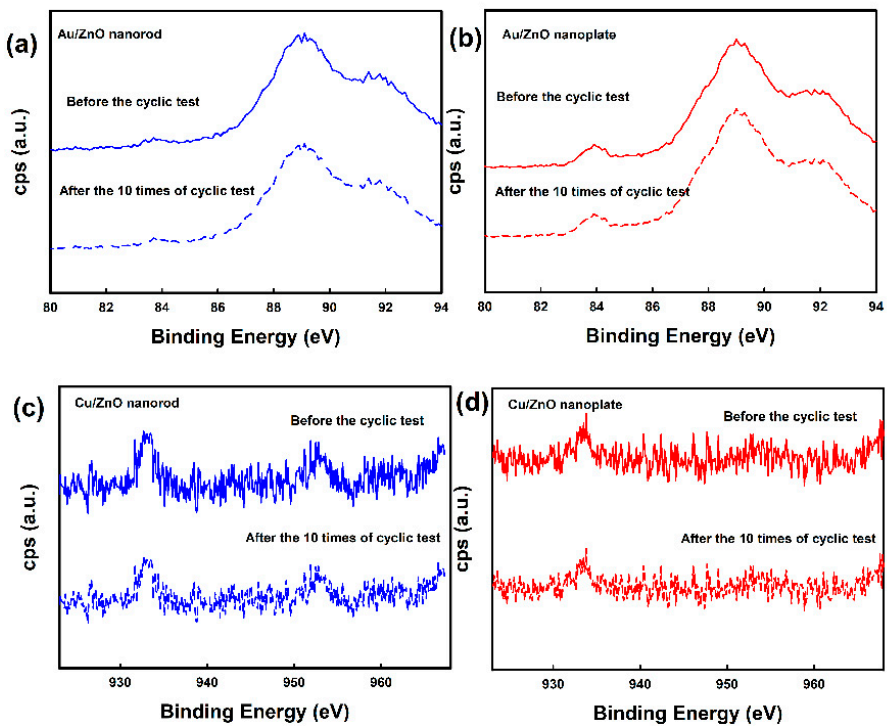

Figure 10. The chemical states of metal deposited $\mathrm{ZnO}$ structures before and after the stability test: (a) $\mathrm{Au} 4 \mathrm{f}$ spectra of $\mathrm{Au} / \mathrm{ZnO}$ nanorod, (b) $\mathrm{Au} 4 \mathrm{f}$ spectra of $\mathrm{Au} / \mathrm{ZnO}$ nanoplate, (c) $\mathrm{Cu} 2 \mathrm{p}$ spectra of $\mathrm{Cu} / \mathrm{ZnO}$ nanorod, and (d) $\mathrm{Cu} 2 \mathrm{p}$ spectra of $\mathrm{Cu} / \mathrm{ZnO}$ nanoplate.

\section{Conclusions}

In this study, we prepared metal-deposited $\mathrm{ZnO}$ nanorod and nanoplate via photodeposition. The CO gas sensitivity is influenced by the combined effect of electrical property such as the work function of deposited-metal and electrical conductivity, the amounts and type of the deposited-metal nanoparticles, and the morphology of the $\mathrm{ZnO}$ nanostructures in metal-deposited $\mathrm{ZnO}$ nanostructures. Among the samples, $\mathrm{Au} / \mathrm{ZnO}$ nanorod showed the best response $(\sim 86 \%)$ to the exposure of $100 \mathrm{ppm}$ 
$\mathrm{CO}$ gas at $200{ }^{\circ} \mathrm{C}$. The result showed that the electrical properties due to the deposition of metal species also have a high influence on the sensor properties such as sensor response, working temperature, the response and recovery time, etc., together with the morphology of $\mathrm{ZnO}$. These findings could be expected to enlarge the understanding of the role of the morphology of sensors and deposited-metal on gas sensitivity.

Supplementary Materials: The following are available online at http://www.mdpi.com/2079-4991/10/11/2124/s1, Figure S1: SEM image of $\mathrm{ZnO}$ nanostructures (a) $\mathrm{ZnO}$ nanorod (b) $\mathrm{ZnO}$ nanoplate, Figure S2: XRD patterns of the samples.

Author Contributions: Conceptualization, S.-H.H. and S.K.L.; data curation, Y.K.K. and S.H.H.; formal analysis, Y.K.K. and S.H.H.; methodology, Y.K.K.; project administration, S.K.L.; supervision, S.K.L.; writing—original draft, S.-H.H. and Y.K.K.; writing-review and editing, S.-H.H. and S.K.L. All authors have read and agreed to the published version of the manuscript.

Funding: This research was funded by DGIST R \& D Program of Ministry of Science and ICT of the Republic of Korea, grant number 20-ET-08.

Conflicts of Interest: The authors declare no conflict of interest.

\section{References}

1. Bleecker, M.L. Chapter 12-Carbon monoxide intoxication. In Handbook of Clinical Neurology; Lotti, M., Bleecker, M.L., Eds.; Elsevier: Amsterdam, The Netherlands, 2015; Volume 131, pp. 191-203.

2. World Health Organization; Regional Office for Europe. WHO Guidelines for Indoor air Quality: Selected Pollutants; World Health Organization: Geneva, Switzerland; Regional Office for Europe: Copenhagen, Denmark, 2010.

3. Choi, K.-W.; Lee, J.-S.; Seo, M.-H.; Jo, M.-S.; Yoo, J.-Y.; Sim, G.S.; Yoon, J.-B. Batch-fabricated CO gas sensor in large-area (8-inch) with sub-10 mW power operation. Sens. Actuators B 2019, 289, 153-159. [CrossRef]

4. Vallejos, S.; Gràcia, I.; Pizúrová, N.; Figueras, E.; Čechal, J.; Hubálek, J.; Cané, C. Gas sensitive ZnO structures with reduced humidity-interference. Sens. Actuators B 2019, 301, 127054. [CrossRef]

5. Naberezhnyi, D.; Rumyantseva, M.; Filatova, D.; Batuk, M.; Hadermann, J.; Baranchikov, A.; Khmelevsky, N.; Aksenenko, A.; Konstantinova, E.; Gaskov, A. Effects of Ag additive in low temperature CO detection with In2O3 based gas sensors. Nanomaterials 2018, 8, 801. [CrossRef]

6. Hsu, K.C.; Fang, T.H.; Tang, I.T.; Hsiao, Y.J.; Chen, C.Y. Mechanism and characteristics of Au-functionalized $\mathrm{SnO} / \mathrm{In} 2 \mathrm{O} 3$ nanofibers for highly sensitive CO detection. J. Alloys Compd. 2020, 822, 9. [CrossRef]

7. Punetha, D.; Pandey, S.K. CO gas sensor based on E-beam evaporated $\mathrm{ZnO}, \mathrm{MgZnO}$, and CdZnO thin films: A comparative study. IEEE Sens. J. 2019, 19, 2450-2457. [CrossRef]

8. Giancaterini, L.; Cantalini, C.; Cittadini, M.; Sturaro, M.; Guglielmi, M.; Martucci, A.; Resmini, A.; Anselmi-Tamburini, $\mathrm{U}$. Au and Pt nanoparticles effects on the optical and electrical gas sensing properties of sol-gel-based $\mathrm{ZnO}$ thin-film sensors. IEEE Sens. J. 2015, 15, 1068-1076. [CrossRef]

9. Schmidt-Mende, L.; MacManus-Driscoll, J.L. ZnO-Nanostructures, defects, and devices. Mater. Today 2007, 10, 40-48. [CrossRef]

10. Dhahri, R.; Hjiri, M.; El Mir, L.; Alamri, H.; Bonavita, A.; Iannazzo, D.; Leonardi, S.G.; Neri, G. CO sensing characteristics of In-doped $\mathrm{ZnO}$ semiconductor nanoparticles. J. Sci. Adv. Mater. Devices 2017, 2, 34-40. [CrossRef]

11. Wang, Y.; Meng, X.-n.; Cao, J.-l. Rapid detection of low concentration CO using Pt-loaded ZnO nanosheets. J. Hazard. Mater. 2020, 381, 120944. [CrossRef]

12. Arunkumar, S.; Hou, T.; Kim, Y.-B.; Choi, B.; Park, S.H.; Jung, S.; Lee, D.-W. Au Decorated ZnO hierarchical architectures: Facile synthesis, tunable morphology and enhanced $\mathrm{CO}$ detection at room temperature. Sens. Actuators B 2017, 243, 990-1001. [CrossRef]

13. Bhati, V.S.; Hojamberdiev, M.; Kumar, M. Enhanced sensing performance of $\mathrm{ZnO}$ nanostructures-based gas sensors: A review. Energy Rep. 2020, 6, 46-62. [CrossRef]

14. Gong, H.; Hu, J.Q.; Wang, J.H.; Ong, C.H.; Zhu, F.R. Nano-crystalline Cu-doped ZnO thin film gas sensor for CO. Sens. Actuators B 2006, 115, 247-251. [CrossRef]

15. Singh, N.; Gupta, R.K.; Lee, P.S. Gold-Nanoparticle-Functionalized In2O3 Nanowires as CO Gas Sensors with a Significant Enhancement in Response. ACS Appl. Mater. Interfaces 2011, 3, 2246-2252. [CrossRef] 
16. Jeong, H.W.; Choi, S.-Y.; Hong, S.H.; Lim, S.K.; Han, D.S.; Abdel-Wahab, A.; Park, H. Shape-dependent charge transfers in crystalline $\mathrm{ZnO}$ photocatalysts: Rods versus plates. J. Phys. Chem. C 2014, 118, 21331-21338. [CrossRef]

17. Kim, Y.K.; Seo, H.-J.; Kim, S.; Hwang, S.-H.; Park, H.; Lim, S.K. Effect of ZnO electrodeposited on carbon film and decorated with metal nanoparticles for solar hydrogen production. J. Mater. Sci. Technol. 2016, 32, 1059-1065. [CrossRef]

18. Hwang, S.-H.; Kim, Y.K.; Hong, S.H.; Lim, S.K. Cu/CuO@ZnO hollow nanofiber gas sensor: Effect of hollow nanofiber structure and P-N junction on operating temperature and sensitivity. Sensors 2019, 19, 3151. [CrossRef] [PubMed]

19. Lim, S.K.; Hwang, S.-H.; Kim, S.; Park, H. Preparation of ZnO nanorods by microemulsion synthesis and their application as a CO gas sensor. Sens. Actuators B 2011, 160, 94-98. [CrossRef]

20. Fageria, P.; Gangopadhyay, S.; Pande, S. Synthesis of $\mathrm{ZnO} / \mathrm{Au}$ and $\mathrm{ZnO} / \mathrm{Ag}$ nanoparticles and their photocatalytic application using UV and visible light. RSC Adv. 2014, 4, 24962-24972. [CrossRef]

21. Kim, Y.K.; Hwang, S.-H.; Jeong, S.M.; Son, K.Y.; Lim, S.K. Colorimetric hydrogen gas sensor based on $\mathrm{PdO} /$ metal oxides hybrid nanoparticles. Talanta 2018, 188, 356-364. [CrossRef]

22. Carabineiro, S.A.C.; Machado, B.F.; Bacsa, R.R.; Serp, P.; Dražić, G.; Faria, J.L.; Figueiredo, J.L. Catalytic performance of $\mathrm{Au} / \mathrm{ZnO}$ nanocatalysts for CO oxidation. J. Catal. 2010, 273, 191-198. [CrossRef]

23. Qin, Z.; Sun, H.; Tang, Y.; Chang, Z.; Yin, S.; Liu, Z. Bio-inspired hierarchical assembly of Au/ZnO decorated carbonized spinach leaves with enhanced photocatalysis performance. J. Alloy. Compd. 2020, 829, 154393. [CrossRef]

24. Jiang, J.; Mu, Z.; Xing, H.; Wu, Q.; Yue, X.; Lin, Y. Insights into the synergetic effect for enhanced $\mathrm{UV} /$ visible-light activated photodegradation activity via $\mathrm{Cu}-\mathrm{ZnO}$ photocatalyst. Appl. Surf. Sci. 2019, 478, 1037-1045. [CrossRef]

25. Peng, S.; Hong, P.; Li, Y.; Xing, X.; Yang, Y.; Wang, Z.; Zou, T.; Wang, Y. Pt decorated SnO2 nanoparticles for high response $\mathrm{CO}$ gas sensor under the low operating temperature. J. Mater. Sci. Mater. Electron. 2019, 30, 3921-3932. [CrossRef]

26. Lin, T.T.; Lv, X.; Li, S.; Wang, Q.J. The Morphologies of the semiconductor oxides and their gas-sensing properties. Sensors 2017, 17, 2779. [CrossRef]

27. Caglar, M.; Ilican, S.; Caglar, Y.; Yakuphanoglu, F. Electrical conductivity and optical properties of ZnO nanostructured thin film. Appl. Surf. Sci. 2009, 255, 4491-4496. [CrossRef]

28. Nagarjuna, Y.; Hsiao, Y.-J. Au doping ZnO nanosheets sensing properties of ethanol gas prepared on MEMS device. Coatings 2020, 10, 945. [CrossRef]

29. Kim, J.-H.; Mirzaei, A.; Kim, H.W.; Kim, S.S. Low power-consumption CO gas sensors based on Au-functionalized SnO2-ZnO core-shell nanowires. Sens. Actuators B 2018, 267, 597-607. [CrossRef]

30. Karami Horastani, Z.; Sayedi, S.M.; Sheikhi, M.H.; Rahimi, E. Effect of silver additive on electrical conductivity and methane sensitivity of SnO2. Mater. Sci. Semicond. Process. 2015, 35, 38-44. [CrossRef]

31. Chang, J.; Ahmad, M.Z.; Wlodarski, W.; Waclawik, E.R. Self-Assembled 3D ZnO Porous Structures with Exposed Reactive \{0001\} Facets and Their Enhanced Gas Sensitivity. Sensors 2013, 13, 8445-8460. [CrossRef]

32. Chen, M.; Wang, X.; Yu, Y.H.; Pei, Z.L.; Bai, X.D.; Sun, C.; Huang, R.F.; Wen, L.S. X-ray photoelectron spectroscopy and auger electron spectroscopy studies of Al-doped ZnO films. Appl. Surf. Sci. 2000, 158, 134-140. [CrossRef]

33. Betty, C.A.; Choudhury, S.; Girija, K.G. Reliability studies of highly sensitive and specific multi-gas sensor based on nanocrystalline SnO2 film. Sens. Actuators B 2014, 193, 484-491. [CrossRef]

34. Lim, S.K.; Hwang, S.-H.; Chang, D.; Kim, S. Preparation of mesoporous In2O3 nanofibers by electrospinning and their application as a CO gas sensor. Sens. Actuators B 2010, 149, 28-33. [CrossRef]

Publisher's Note: MDPI stays neutral with regard to jurisdictional claims in published maps and institutional affiliations. 